\title{
Embedded Controlled Isolated Bidirectional Full-Bridge DC-DC Converter with Flyback Snubber
}

\author{
D. Kirubakaran ${ }^{1}$ and Rama Reddy Sathi ${ }^{2}$ \\ ${ }^{1}$ EEE Department, St. Joseph's Institute of Technology, Affiliated to Anna University, Chennai-600119, India \\ ${ }^{2}$ Jerusalem College of Engineering, Anna University Chennai, Chennai 600 100, India
}

Correspondence should be addressed to D. Kirubakaran, kiruba_d@yahoo.com

Received 10 May 2012; Revised 16 July 2012; Accepted 31 July 2012

Academic Editor: C. M. Liaw

Copyright (C) 2012 D. Kirubakaran and R. R. Sathi. This is an open access article distributed under the Creative Commons Attribution License, which permits unrestricted use, distribution, and reproduction in any medium, provided the original work is properly cited.

\begin{abstract}
An isolated bidirectional full-bridge DC-DC converter with flyback snubber for supplying a resistive load is simulated and experimentally verified. The DC-DC converter for high conversion ratio, high output power, and soft start-up capability is presented in this paper. The circuit consists of a capacitor, a diode, and a flyback converter. These components help to clamp the voltage spikes caused by the current difference between the current fed inductor and leakage inductance of the isolation transformer. The switches are operated by soft-switching technology. The suppression of inrush current which is usually found in the boost mode start-up transition is presented here. The simulated and experimental results for output voltage, output current, and power for both buck and boost modes are presented.
\end{abstract}

\section{Introduction}

A DC-DC converter converts a source of direct current (DC) from one voltage level to another. These converters are important in portable electronic devices such as cellular phones and laptop computers, which are supplied with power from batteries primarily. The ordinary circuit of a DCDC converter for high power applications typically includes a bidirectional full-bridge DC-DC converter [1-3]. The current difference between the inductor and isolation transformer does not ensure a well-defined output voltage and is characterized by less reliability and efficiency. The output voltage contains voltage spikes. An active commutation can be used to control the current in the leakage inductance [4]. But it requires an additional clamping circuit to suppress the voltage spikes. An RCD passive snubber can be used to clamp the voltage. A buck converter was employed to replace RCD snubber. But it still needed complex clamping circuit $[5,6]$. Active clamping increases the current stress on switches. Soft-switching capability can be used, but it is not suitable for step-down operation.

In this scheme of DC-DC converter with flyback snubber (Figure 1), the snubber recycles the absorbed energy in the clamping capacitor. The voltage of the clamping capacitor can be regulated by operating the flyback snubber independently. The current does not circulate through the fullbridge switches, and hence the current stress can be reduced, improving the system reliability significantly.

\section{Configuration and Operation}

The operating principle of the circuit consists of two modes:

(i) step-up conversion,

(ii) step-down conversion.

The modes of operation of boost mode are shown in Figure 2 and of buck mode in Figure 4. The theoretical waveform for boost and buck modes is shown in Figures 3 and 5, respectively. Initially all components are assumed to be ideal, and the transformer is treated as an ideal transformer associated with leakage inductance.

\subsection{Step-Up Conversion}

Interval 1: $t_{0} \leq t<t_{1}$. The equivalent circuit is shown in Figure 3(a). All the four switches $M_{1}$ and $M_{4}$ are turned ON. 


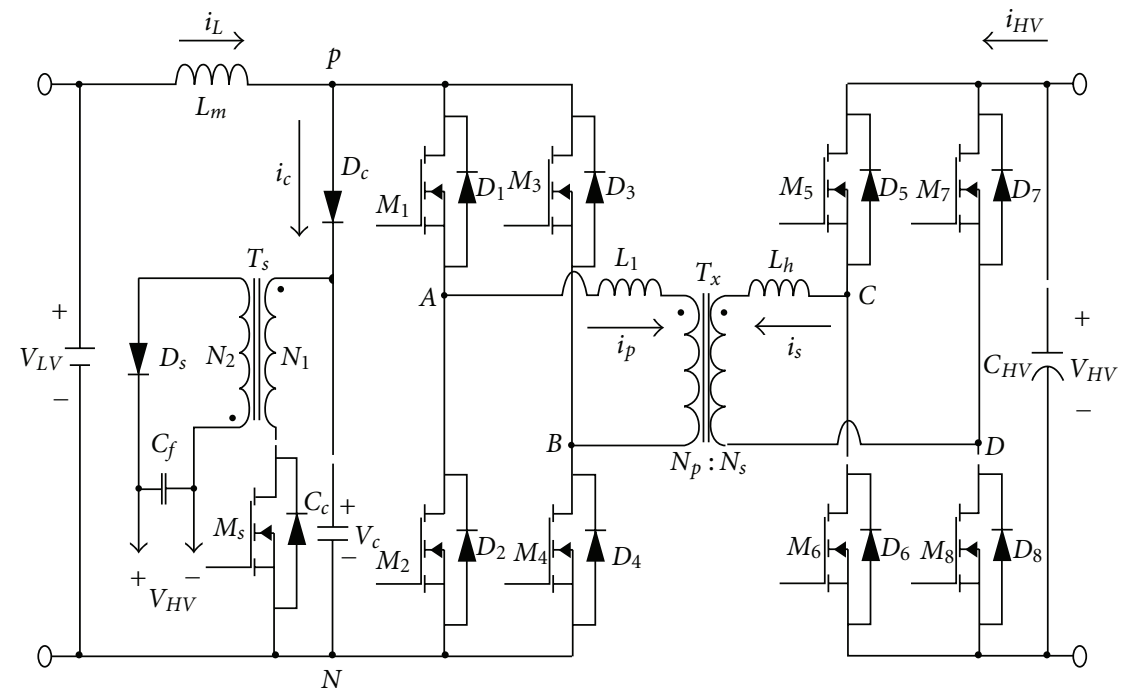

FIGURE 1: Isolated bidirectional full-bridge Dc-Dc converter with flyback snubber.

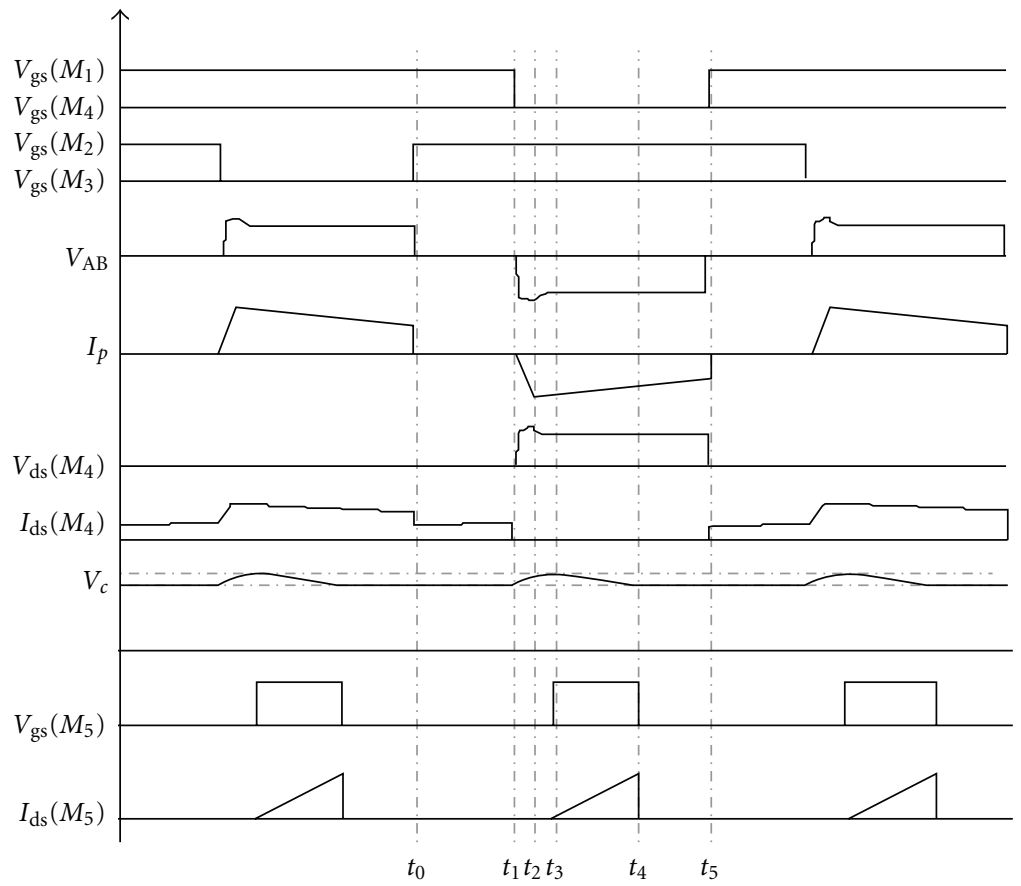

FIGURE 2: Operational waveform of step-up conversion.

In this interval, the inductor $L_{m}$ is charged by $V_{L V}$ and the current $i_{L}$ increases linearly. The primary windings of the transformer are short circuited.

Interval 2: $t_{1} \leq t<t_{2}$. The equivalent circuit is shown in Figure 3(b). At $t_{1}, M_{1}$ and $M_{4}$ are conducting while $M_{2}$ and $M_{3}$ are turned OFF. Clamping diode DC conducts until the current difference $\left(i_{L}\left(t_{2}\right)-i_{p}\left(t_{2}\right)\right)$ drops to zero. $D_{5}$ and $D_{8}$ conduct to transfer power. The current difference $\left(i_{L}(t)-\right.$ $\left.i_{p}(t)\right)$ flows into clamping capacitor $C_{c}$.

Interval 3: $t_{2} \leq t<t_{3}$. The equivalent circuit is shown in Figure $3(\mathrm{c})$. At $t_{2}$, DC stops conducting and flyback snubber starts to operate. Clamping capacitor $C_{c}$. is discharging and flyback conductor stores energy. $M_{1}$ and $M_{4}$ in ON state and $\mathrm{D}_{5}$ and $\mathrm{D}_{8}$ remain $\mathrm{ON}$ to transfer power.

Interval 4: $t_{3} \leq t<t_{4}$. The equivalent circuit is shown in Figure $3(\mathrm{~d})$. At $t_{3}$, the energy stored in flyback conductor is transferred to high-voltage side. The flyback snubber operates to regulate $V_{L V}$ to $V_{c}$ to $V_{c(R)}$ same switches operates to transfer power from $V_{L V}$ to $V_{H V}$.

Interval 5: $t_{4} \leq t<t_{5}$. The equivalent circuit is shown in Figure 3(e). At $t_{4}$, we obtain a regulated voltage $V_{c(R)}$. The main power stage 


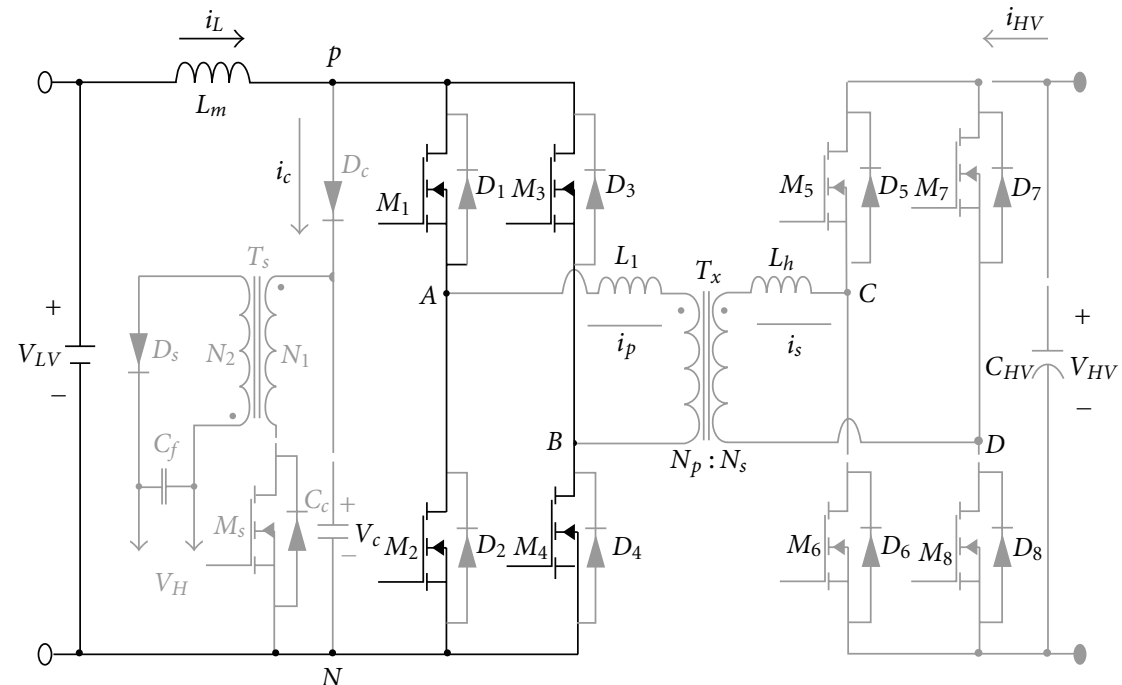

(a) Mode I $\left(t_{0}-t_{1}\right)$

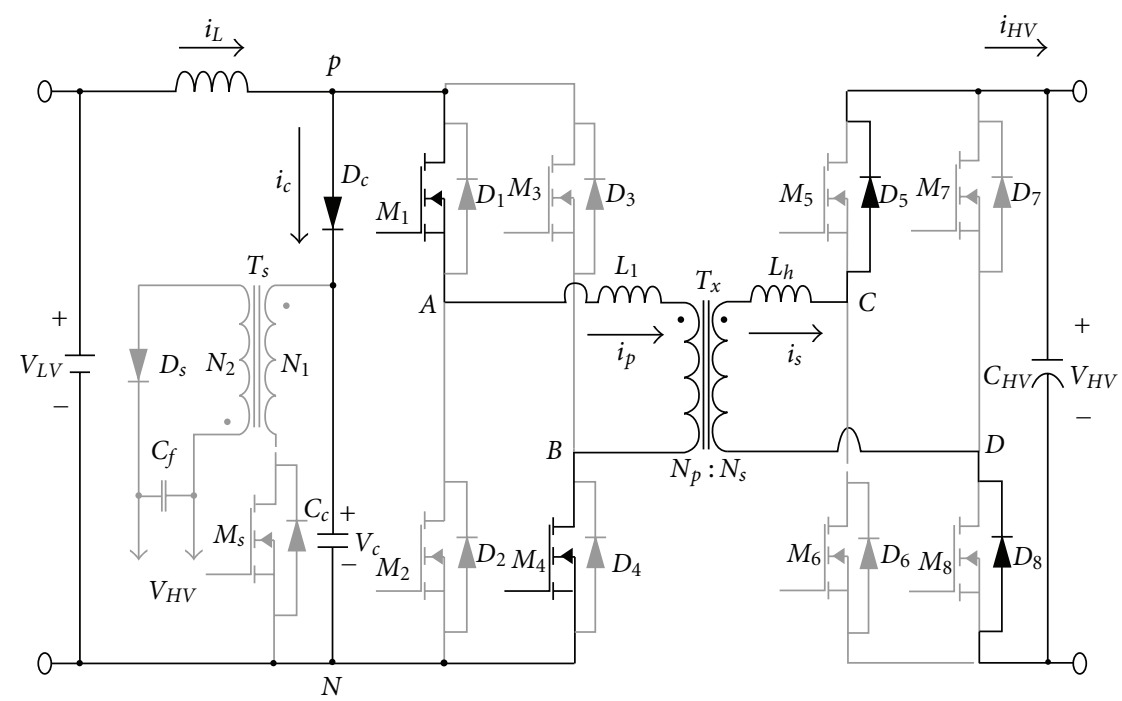

(b) Mode II $\left(t_{1}-t_{2}\right)$

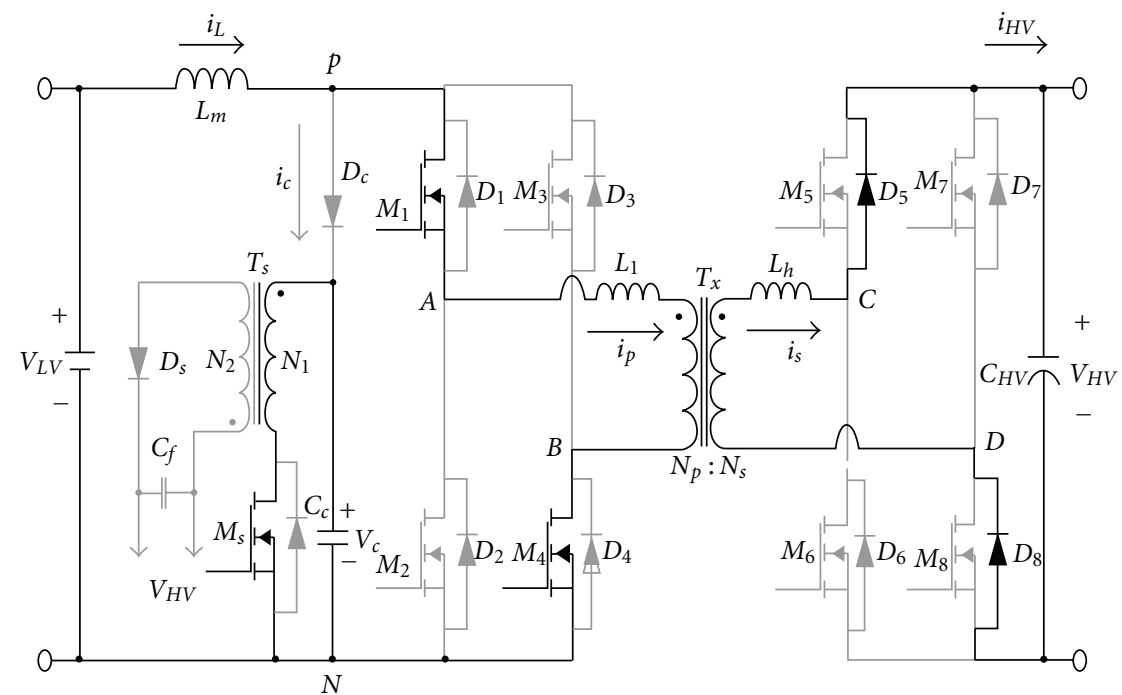

(c) Mode III $\left(t_{2}-t_{3}\right)$

Figure 3: Continued. 


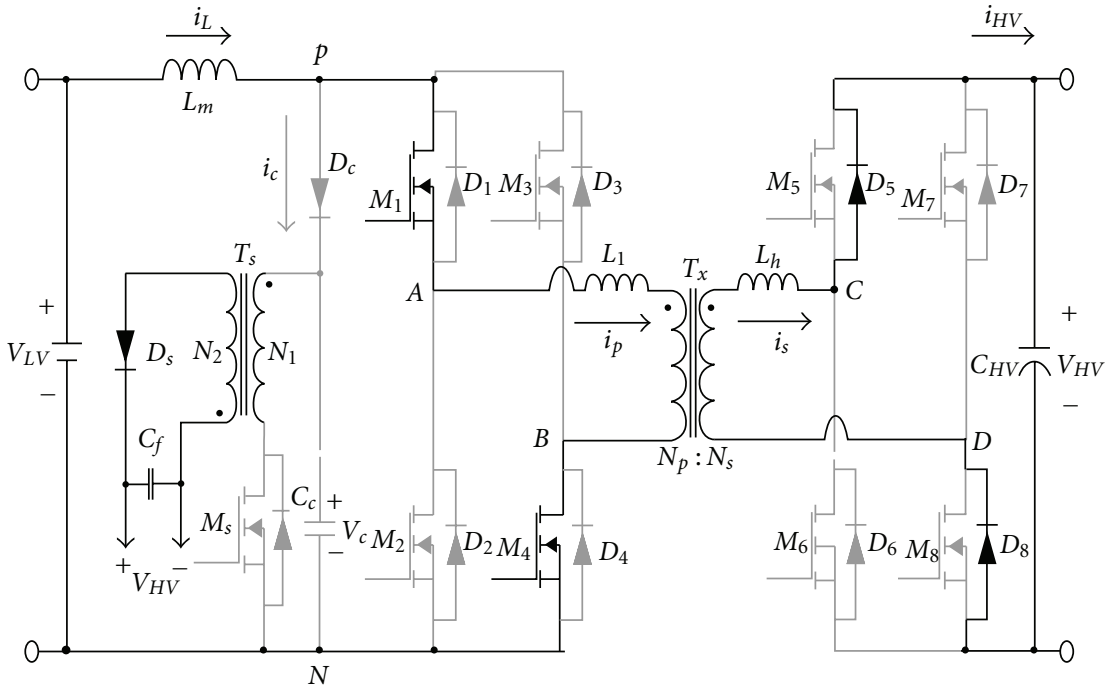

(d) Mode IV $\left(t_{3}-t_{4}\right)$

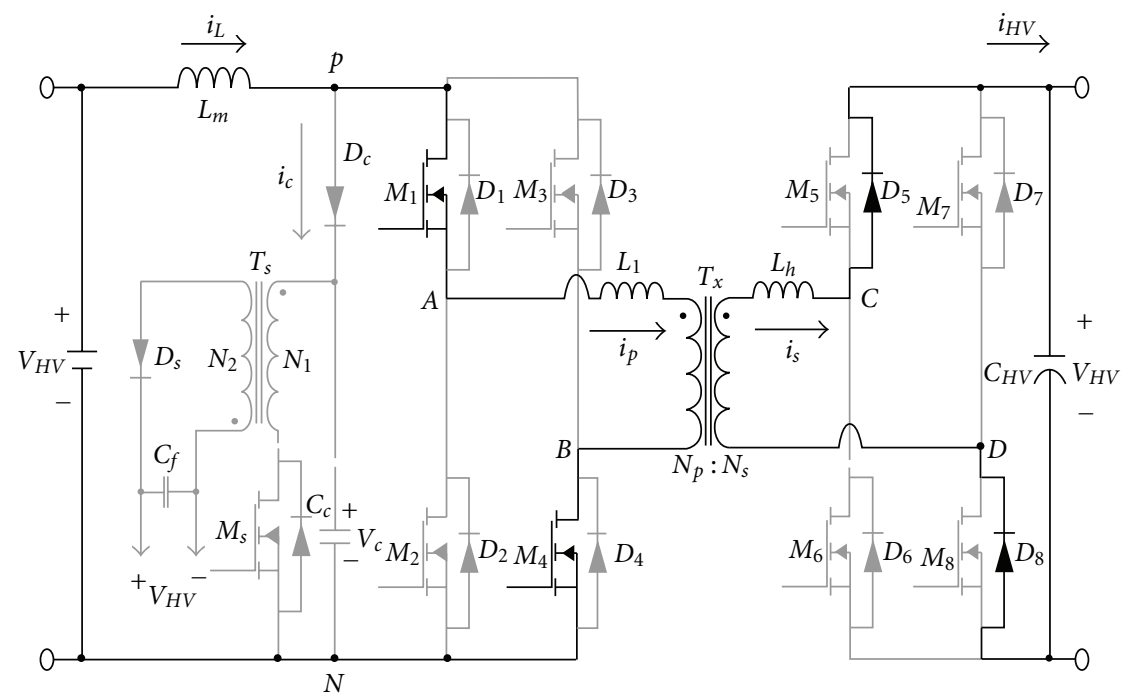

(e) Mode V $\left(t_{4}-t_{5}\right)$

FIgURE 3: Equivalent circuit for step-up conversion.



Figure 4: Operation waveforms of step-down conversion. 




(a) Mode I $\left(t_{0}-t_{1}\right)$

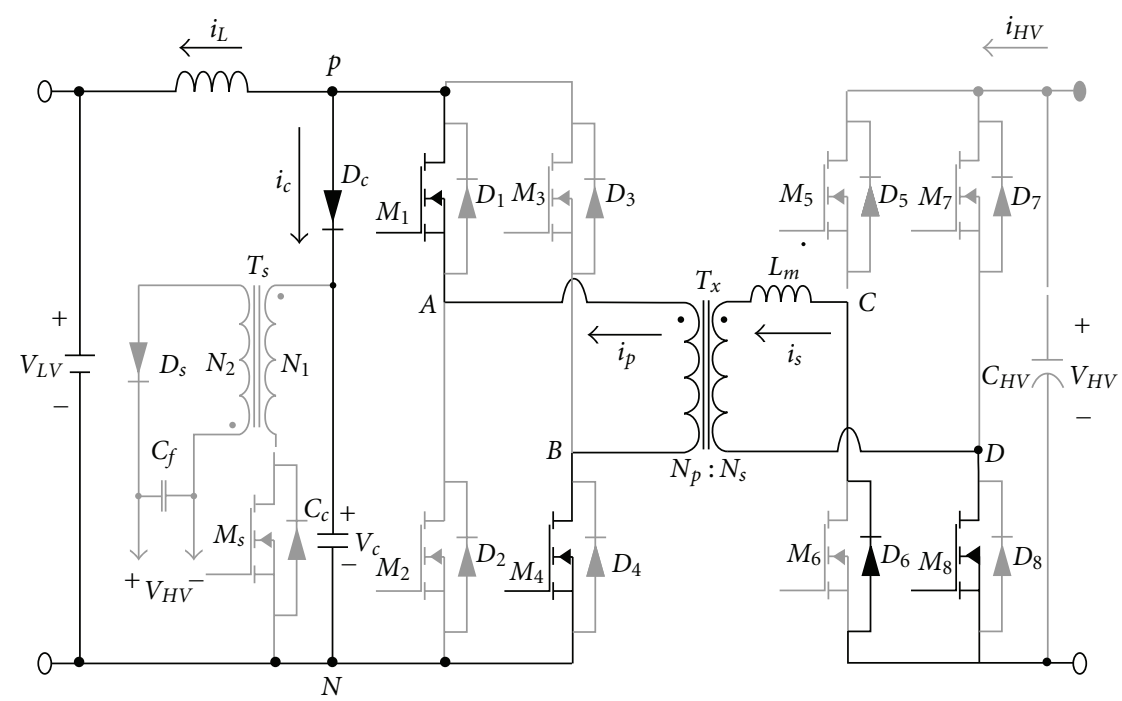

(b) Mode II $\left(t_{1}-t_{2}\right)$

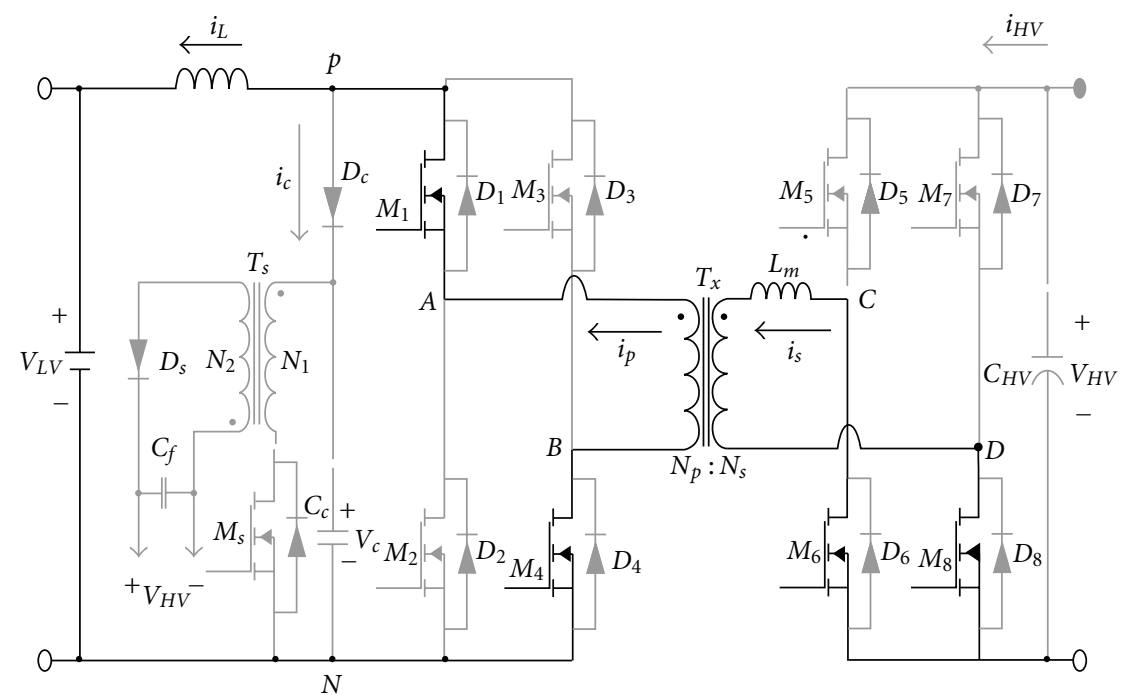

(c) Mode III $\left(t_{2}-t_{3}\right)$

Figure 5: Continued. 


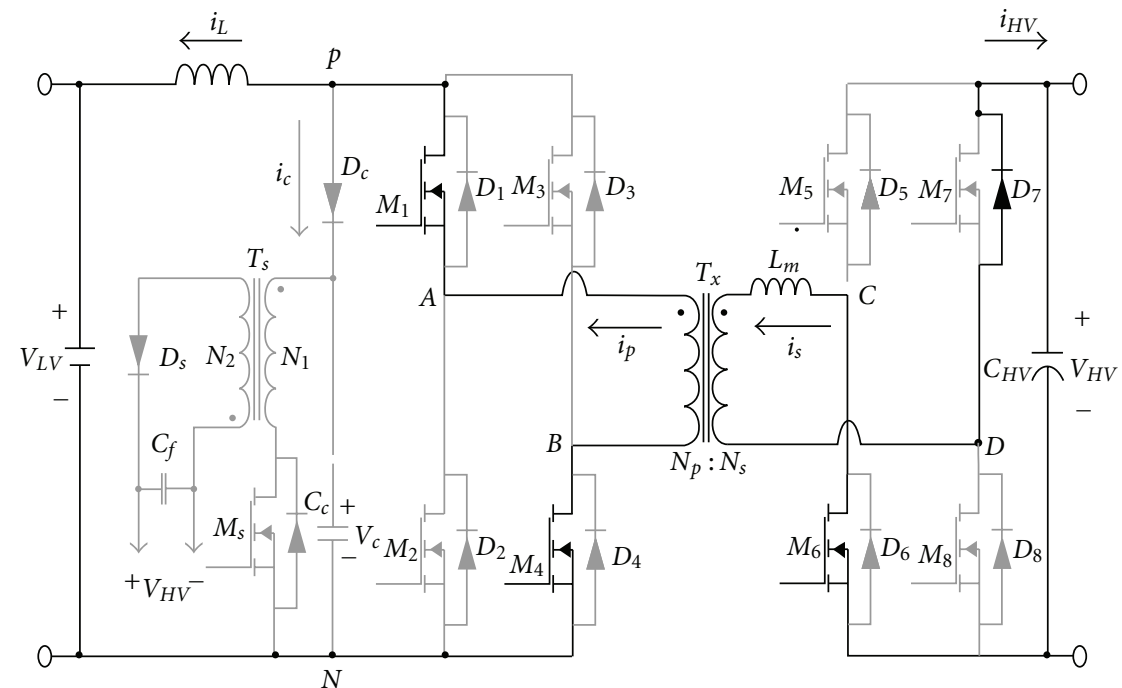

(d) Mode IV $\left(t_{3}-t_{4}\right)$

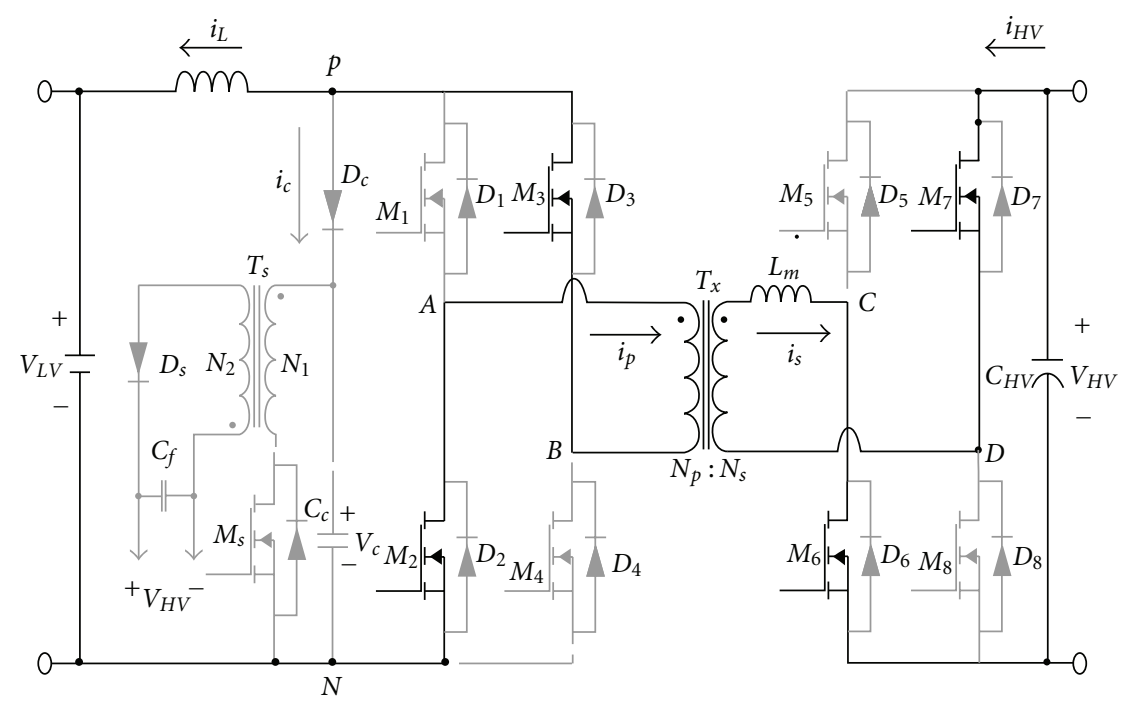

(e) Mode $\mathrm{V}\left(t_{4}-t_{5}\right)$

Figure 5: Equivalent circuit for step-down conversion.

is still transferring power from $V_{L V}$ to $V_{H V}$. It stops at $t_{5}$ and a half switching cycle operation is completed.

\subsection{Step-Down Conversion}

Interval 1: $t_{0} \leq t<t_{1}$. The equivalent circuit is shown in Figure 5(a). At $t_{0}, M_{5}$ and $M_{8}$ are turned $\mathrm{ON}$. The $V_{H V}$ is immediately excited on the transformer and the whole voltage is exerted on Leq. The transformer current increases linearly towards the load current at $t_{1} . M_{1}$ and $M_{4}$ conduct to transfer power.

Interval 2: $t_{1} \leq t<t_{2}$. The equivalent circuit is shown in Figure 5(b). At $t_{1}, M_{8}$ remains conducting while $M_{5}$ is turned OFF. $D_{6}$ conducts the freewheeling leakage current.
The transformer current reaches the load current level at $t_{1}$. DC conducts the resonant Leq and the clamping capacitor $\mathrm{C}_{\mathrm{c}}$.

Interval 3: $t_{2} \leq t<t_{3}$. The equivalent circuit is shown in Figure $5(\mathrm{c})$. At $t_{2}$, with diode $D_{6}$ conducting, $M_{6}$ is turned $\mathrm{ON}$ with zero voltage switching.

Interval 4: $t_{3} \leq t<t_{4}$. The equivalent circuit is shown in Figure $5(\mathrm{~d})$. At $t_{3}, M_{6}$ remains conducting while $M_{8}$ is turned OFF. The diode $D_{7}$ starts to conduct the freewheeling leakage current.

Interval 5: $t_{4} \leq t<t_{5}$. The equivalent circuit is shown in Figure $5(\mathrm{~d})$. At $t_{4}$, with $D_{7}$ conducting, $M_{7}$ is turned $\mathrm{ON}$ with ZVS. Over this interval, the active switches change to 


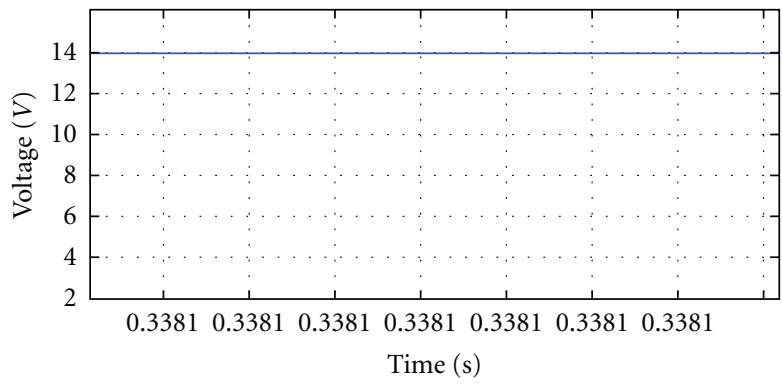

(a)
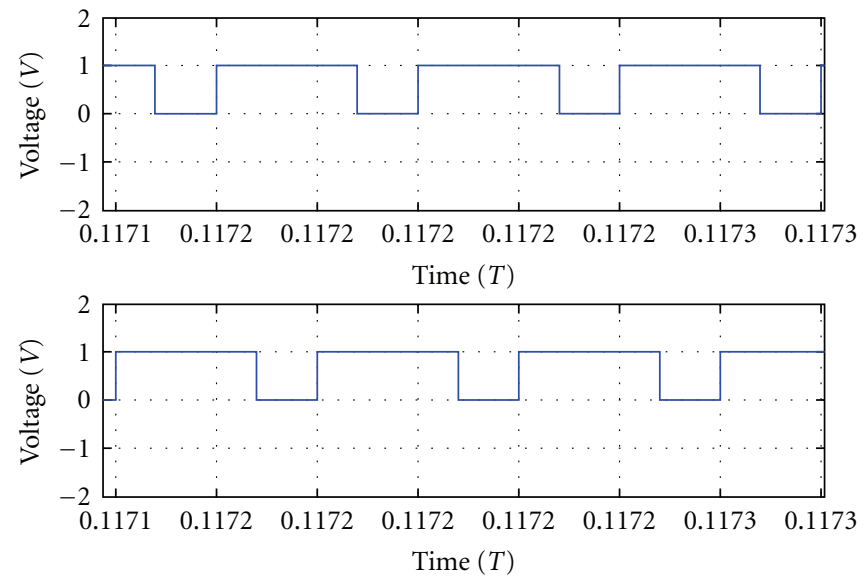

(b)

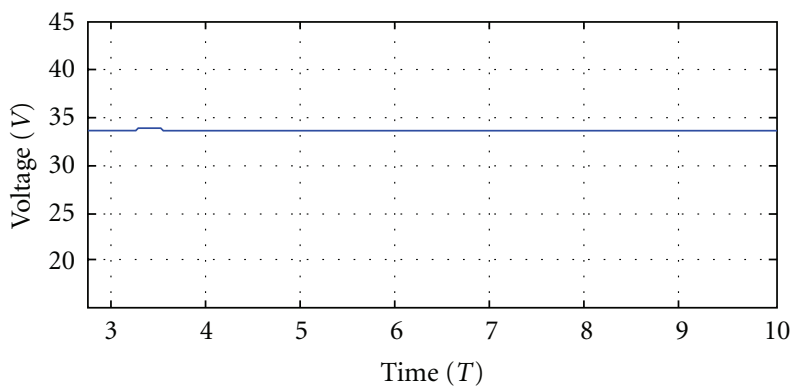

(c)

FIGURE 6: Simulation circuit and results. (a) Input voltage for boost mode. (b) Driving pulse for switches $M_{1}$ and $M_{2}$. (c) Output voltage for boost mode.

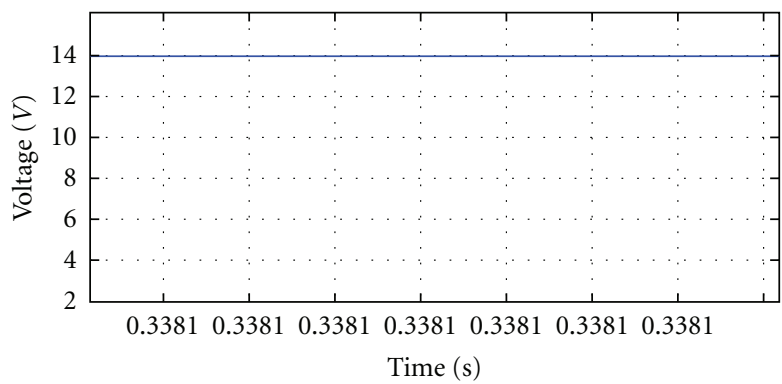

(a)
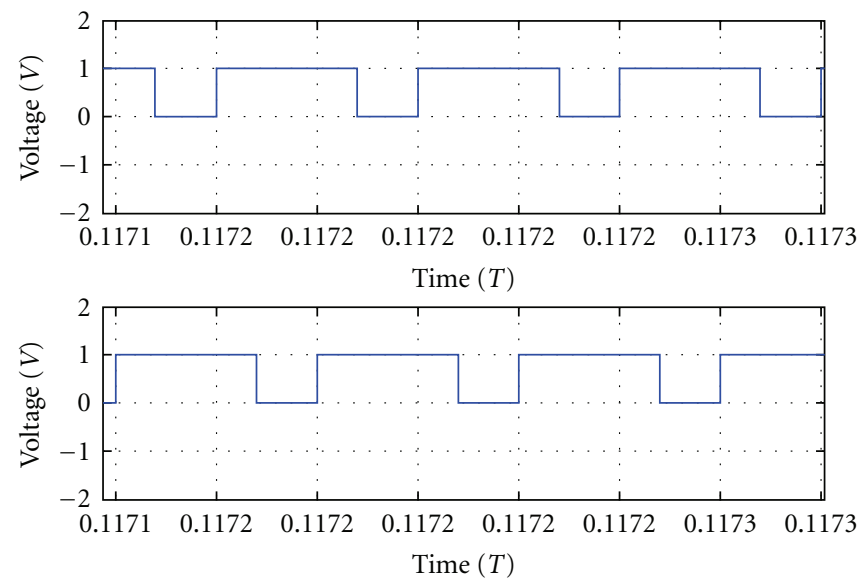

(b)

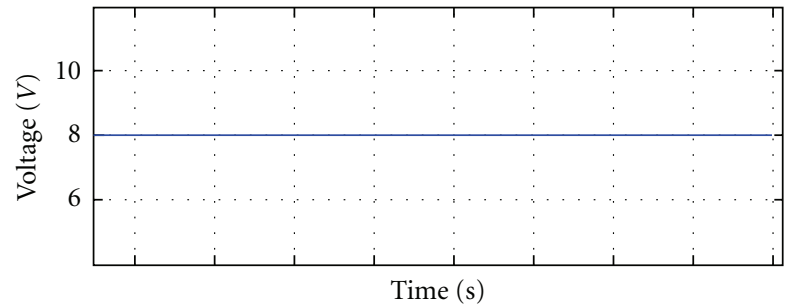

(c)

Figure 7: Simulation circuit and results. (a) Input voltage for buck mode. (b) Driving pulse for switches $M_{1}$ and $M_{2}$. (c) Output voltage for buck mode. 


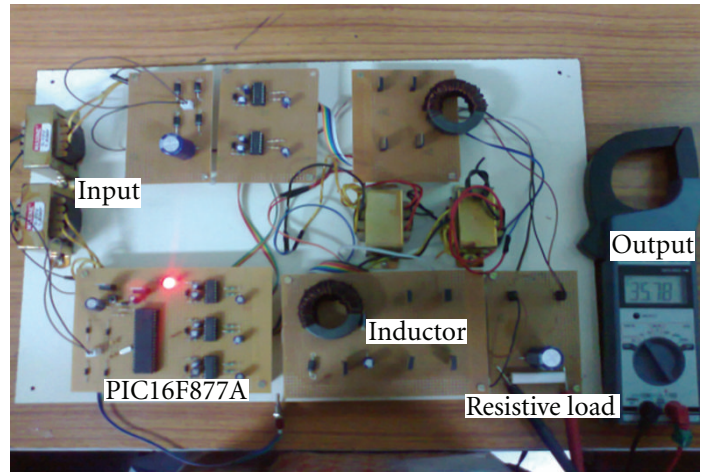

(a)

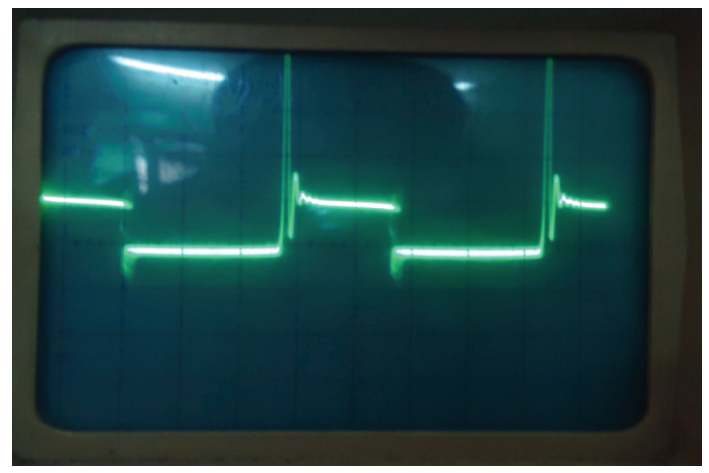

(c)

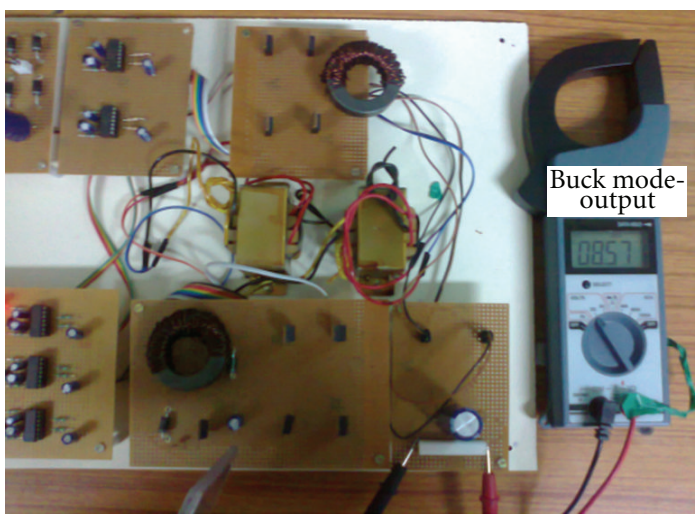

(e)

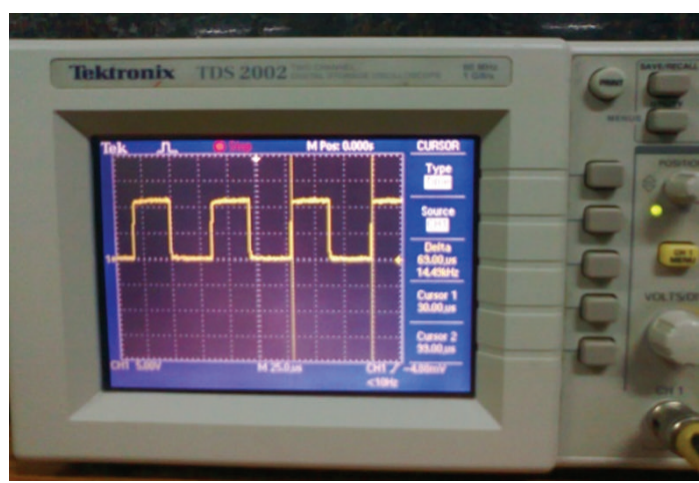

(b)



(d)

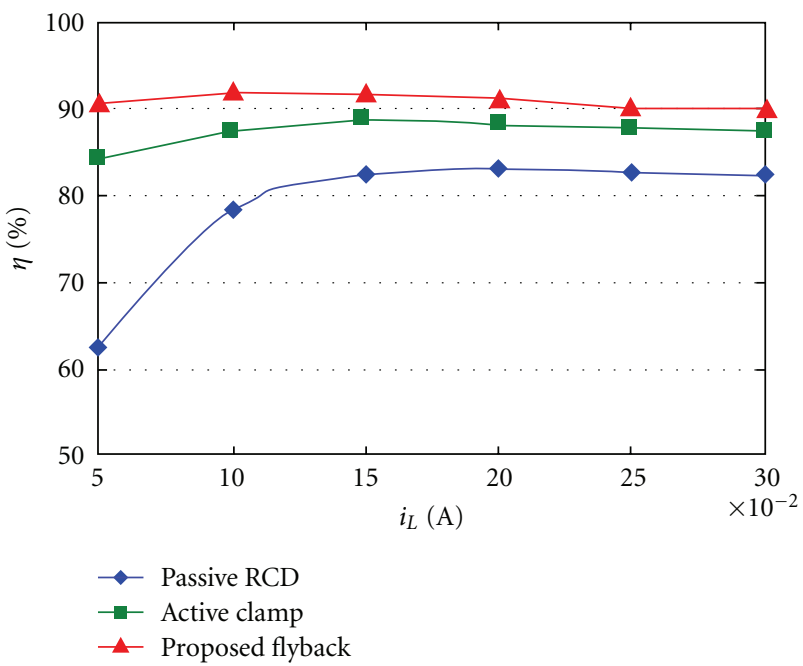

(f)

Figure 8: Hardware layout and results. (a) Photograph of the prototype converter. (b) Switching pulse of switch, S1. (c) Transformer primary side voltage. (d) Transformer secondary side voltage. (e) Converter with buck output. (f) Plot of efficiency in step-up mode.

the other pair of diagonal switches, and the voltage and the transformer reverse its polarity. It stops at $t_{5}$ and it completes a half switching cycle operation.

\section{Simulation}

The full-bridge DC-DC converter with flyback snubber is simulated using the Matlab Simulink results presented here. The Simulation parameters are shown in Table 1. Scopes are connected to measure $\mathrm{I} / \mathrm{P}$ voltage, driving pulses, and $\mathrm{O} / \mathrm{P}$ voltage. Switching pulses are shown in Figure 6(b). This is the switching pulse given to the MOSFET switches. The output voltage is shown in Figure 6(c).

For the buck mode with resistor as the load, switching pulses are shown in Figure 7(b). Input and the output voltage are shown in Figures 7(a) and 7(c), respectively. 


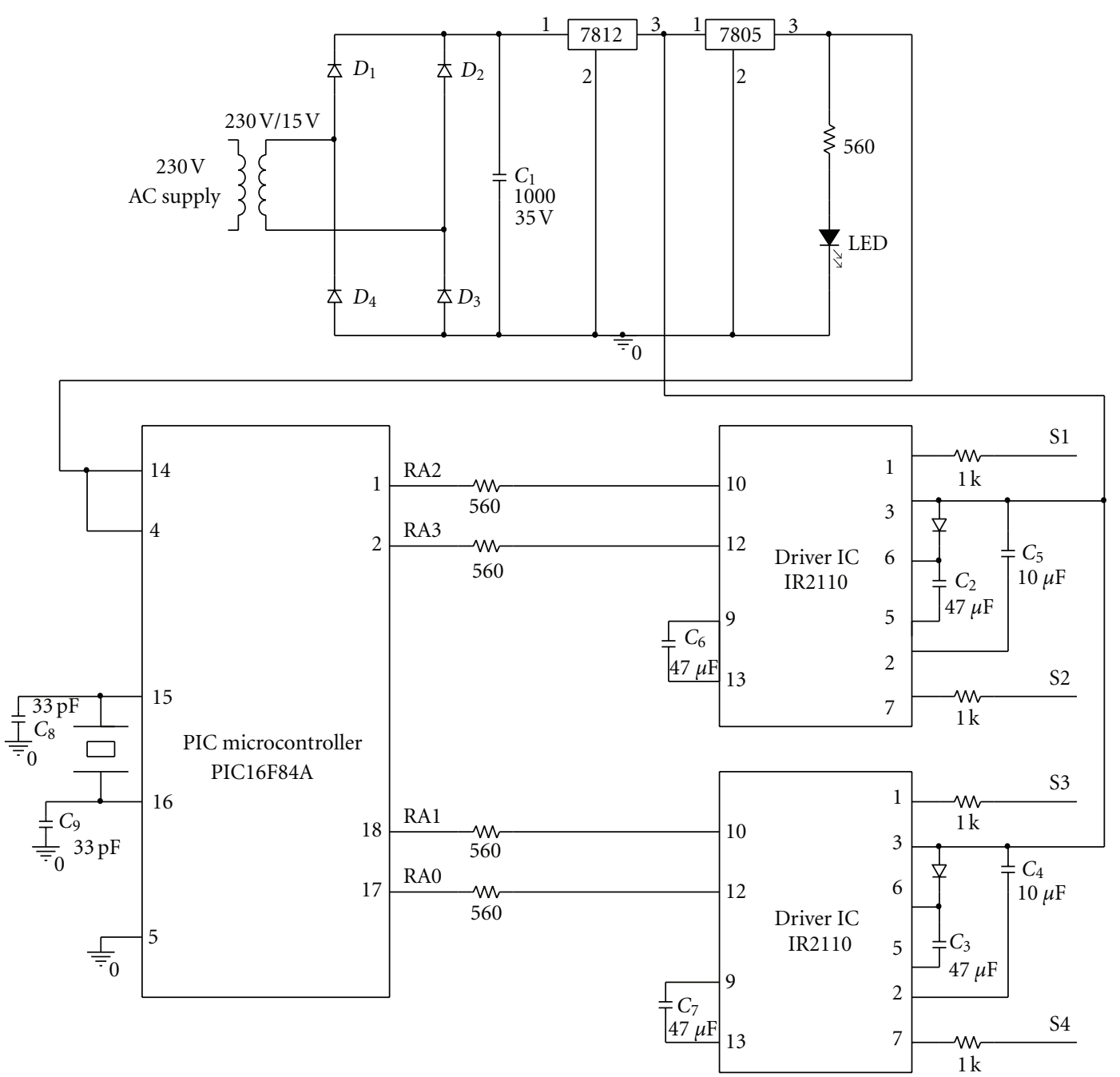

(a)

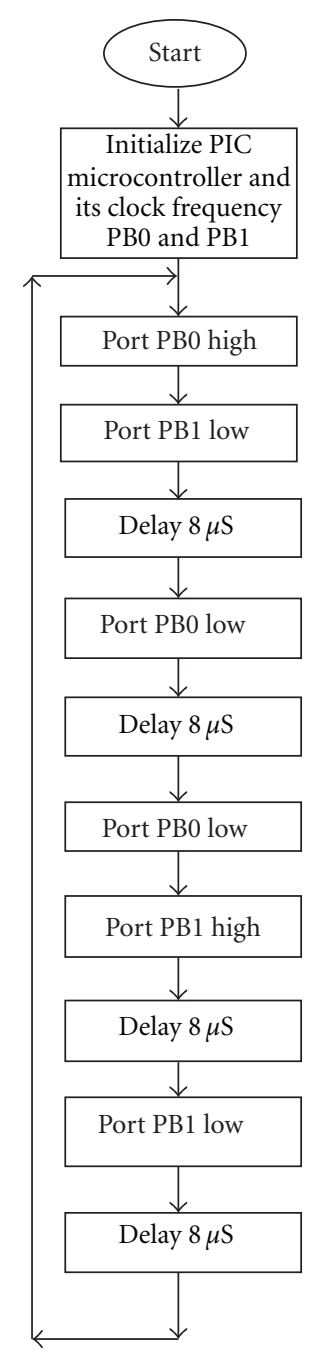

(b)

FIGURE 9: (a) PIC-based control circuit. (b) Flow chart.

TABLE 1: Simulation parameters.

\begin{tabular}{lcc}
\hline Input voltage & $V_{\text {in }}$ & $15(\mathrm{~V})$ \\
Output voltage & $V_{\mathrm{o}}$ & $33(\mathrm{~V})$ \\
Switching frequency & $F_{s}$ & $8(\mathrm{kHz})$ \\
Filter capacitor & $C 1$ & $2200(\mu \mathrm{F})$ \\
Flyback capacitor & $C 2$ & $100(\mu \mathrm{F})$ \\
Main inductor & $L 1$ & $20(\mu \mathrm{H})$ \\
Filter inductor & $L 2$ & $5(\mu \mathrm{H})$ \\
\hline
\end{tabular}

The PIC 16F876S microcontroller can be used to generate the driving pulse for MOSFET switches. Thus the PIC circuit acts as the control circuit.

\section{Experimental Results}

The input $230 \mathrm{~V}$ is stepped down to $15 \mathrm{~V}$ using a step-down transformer and it is rectified to DC by the bridge rectifier. In boost mode, the output of the rectifier is boosted by a step-up transformer of ratio $1: 2$. The output is converted into ac by an inverter. The load used is a resistive load of rating $1 \mathrm{~K}, 10 \mathrm{~W}$. The output of the flyback converter is fed to the load through a series connection. The output in boost mode is $35 \mathrm{~V}$. In buck mode, the input $15 \mathrm{~V}$ is stepped down to $8 \mathrm{~V}$. Figure 8 (a) shows the photograph of the prototype converter with boosted output. The switching frequency is $20 \mathrm{KHz}$ and the switching pulse of switch, S1, is shown in Figure $8(\mathrm{~b})$. The primary side voltage of the transformer is measured to be $15 \mathrm{~V}$. In the boost mode it is boosted to $30 \mathrm{~V}$ and it is shown in Figure 8(c). The output of the buck mode is shown in Figure 8(e). The output is measured using a multimeter and it is $8.5 \mathrm{~V}$. Figure $8(\mathrm{f})$ shows the plot of conversion efficiency of the bidirectional converter with various snubbers operated in the step-up mode.

It can be observed that the conversion efficiency of the proposed converter is around 90-92\%, which is higher than the other types.

The PIC 16X7X-based control circuit is shown in Figure 9(a). The microcontroller is used to generate driving 
pulses for the MOSFET switches. They are amplified using the driver IC IR2110. The gate signal is connected to port pin P1.0. Various steps involved in the firing pulse generation are shown in Figure 9(b).

\section{Conclusion}

An isolated bidirectional full-bridge DC-DC converter transformer converter had voltage spikes due to the current difference between the current fed inductor and leakage inductance of the isolation transformer. This voltage spike has been alleviated by the flyback snubber. The flyback snubber can be controlled to attain a soft start-up feature. The current stress is reduced under heavy load conditions. This converter has also the advantage of increased reliability and efficiency. The simulation demonstrates the actual converter capability to alleviate voltage spikes and to improve the efficiency.

\section{References}

[1] H. Bai and C. Mi, "Eliminate reactive power and increase system efficiency of isolated bidirectional dual-active-bridge DCDC converters using novel dual-phase-shift control," IEEE Transactions on Power Electronics, vol. 23, no. 6, pp. 2905-2914, 2008.

[2] B. Bai, C. C. Mi, and S. Gargies, "The short-time-scale transient processes in high-voltage and high-power isolated bidirectional DC-DC converters," IEEE Transactions on Power Electronics, vol. 23, no. 6, pp. 2648-2656, 2008.

[3] C. Zhao, S. D. Round, and J. W. Kolar, "An isolated three-port bidirectional DC-DC converter with decoupled power flow management," IEEE Transactions on Power Electronics, vol. 23, no. 5, pp. 2443-2453, 2008.

[4] T. Reimann, S. Szeponik, G. Berger, and J. Petzoldt, "Novel control principle of bi-directional DC-DC power conversion," in Proceedings of the 28th Annual IEEE Power Electronics Specialists Conference (PESC '97), vol. 2, pp. 978-984, June 1997.

[5] C. Qiao and K. M. Smedley, "An isolated full bridge boost converter with active soft switching," in Proceedings of the IEEE 32nd Annual Power Electronics Specialists Conference, pp. 896903, June 2001.

[6] L. Zhou and X. Ruan, "A zero-current and zero-voltage-switching PWM boost full-bridge converter," in Proceedings of the IEEE 34th Annual Power Electronics Specialists Conference, pp. 957-962, June 2003. 



Submit your manuscripts at

http://www.hindawi.com
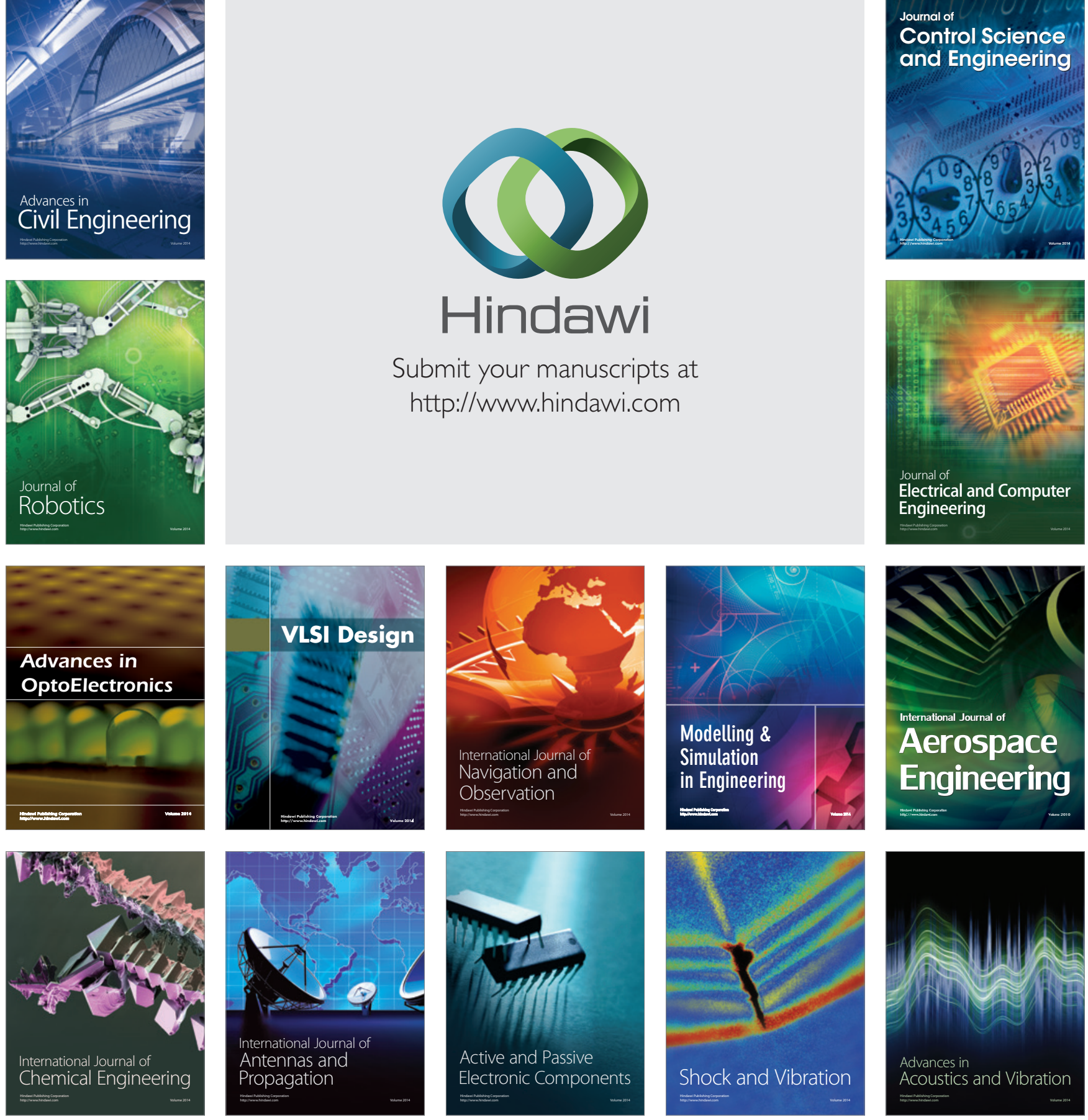